\author{
Recommendations for Interviewing Children about Repeated Experiences \\ Martine B. Powell ${ }^{\mathrm{a}}$, Sonja P. Brubacher ${ }^{\mathrm{b}}$, Kim P. Roberts ${ }^{\mathrm{c}}$ \\ ${ }^{\mathrm{a} D e a k i n}$ University, ${ }^{\mathrm{b}}$ Central Michigan University, ${ }^{\mathrm{c}}$ Wilfrid Laurier University
}

\begin{abstract}
Author Note:
Author Note: Preparation of this article was supported in part by an Australian Research Linkage Grant LP120200095 to MBP and KPR and a Canada Banting Postdoctoral Fellowship to SPB. ${ }^{a}$ Correspondence and reprint requests should be addressed to Martine Powell, School of Psychology, Deakin University, 221 Burwood Highway, Burwood Victoria, 3125, +61 3924 46106, martine.powell@ deakin.edu.au. ${ }^{b}$ Department of Psychology, Sloan Hall, Central Michigan University, Mount Pleasant, MI, 48859, bruba1sp@cmich.edu. ${ }^{\mathrm{c} D e p a r t m e n t ~ o f ~}$ Psychology, Wilfrid Laurier University, 75 University Ave W, Waterloo, ON, N2L 3C5, kroberts@wlu.ca. $\quad$ Transcripts have been modified for illustrative purposes and, although representative, are not direct quotes from any individual child.
\end{abstract}




\begin{abstract}
For just over two decades, researchers have been conducting empirical studies devoted to understanding children's memory for, and ability to describe, individual occurrences of events they have experienced repeatedly. This knowledge is critical because children making allegations of repeated abuse are required to provide details particular to an individual incident in many jurisdictions internationally. Based on this theoretical foundation, we provide specific suggestions to practitioners to assist children in reporting as much information as possible about individual occurrences and techniques that may assist them in doing so accurately. These recommendations cover both presubstantive (i.e., "practice") and substantive phases of the interview. The particular challenges involved with describing individual incidents of repeated events are discussed, followed by evidence-based guidelines aimed at overcoming these difficulties. The inaugural guidelines we present are not meant as a replacement to existing best practice interviews, but to serve as more detailed procedures in cases of repeated allegations.
\end{abstract}




\section{Recommendations for Interviewing Children about Repeated Experiences}

Across the globe, a high proportion of child sexual abuse cases concern multiple abuses (Connolly \& Read, 2006; Finkelhor, 1979; Sas \& Cunningham, 1995). For example, the most recent Canadian Incidence Study (CIS-4) revealed that $51 \%$ of reported child sexual abuse cases involved multiple incidents (Trocmé et al., 2010). In many jurisdictions worldwide, successful prosecution of an offender charged with multiple incidents of perpetrating child sexual abuse depends upon the child victim's ability to specify one or more individual acts of exploitation with respect to time, place, type of abuse, and other unique contextual details (Guadagno, Powell, \& Wright; 2006; Podirsky v R., 1990; R. v B. [G.], 1990; S v. R, 1989).

Even where particularization is not mandatory, children's credibility is enhanced by providing organized episodic narratives (Burrows \& Powell, 2013; Davis, Hoyano, Keenan, Maitland \& Morgan, 1999; Smith \& Milne, 2011). Children's abilities to particularize individual acts of sexual abuse, therefore, are often either necessary or highly beneficial to the successful prosecution of child abuse offenders. As we will explain, recalling one individual occurrence from a set of repeated experiences is a difficult task. We first discuss the challenges for children associated with remembering and reporting specific occurrences of abuse followed by guidelines for interviewers in facilitating this process.

\section{Challenges in Retrieving Individual Occurrences}

The type of memory that results from repeated experience of an event has different qualities than memory for events only experienced once (see Roberts \& Powell, 2001, for a review). When events are experienced repetitively, people develop a 'script' about what usually happens (Hudson, Fivush \& Kuebli, 1992; Hudson \& Mayhew, 2009; Nelson, 1986). Scripts are organized mental structures that describe typical event actions or objects, and can include 
information about the order in which they happened (Abelson, 1981; Schank \& Abelson, 1977).

When people recount script information they use the timeless present-tense ('generic language') and often refer to optional elements (e.g., "sometimes x, sometimes y") (Nelson \& Gruendel, 1981). Scripts frequently also include use of the impersonal-you pronoun (e.g., "you order food at a restaurant"). It is highly typical and normal for both children and adults to form scripts for events they have experienced (Fivush, 1984; see Schank \& Abelson, 1977, for a review), and the reliance on scripts to aid memory tends to increase over long delays (Myles-Worsley, Cromer, \& Dodd, 1986; Slackman \& Nelson, 1984). Retrieval of individual occurrences from the script must be derived through episodic recollection (i.e., consciously re-experiencing the individual event, thinking about the "when" and the "where"; Tulving, 2000a; Tulving \& Markowitsch, 1998). In contrast, retrieval of well-known script information is more akin to a semantic process (i.e., thinking about what is 'known' without needing to retrieve specific details; Tulving, 2000b). Consider the following report from a child-victim:

C: Whenever mum goes out, like sometimes she works in the evenings, he-, she works on Wednesday, Thursday, and Friday nights, whenever she goes he just comes in, like while I'll be watching TV or something, and does the thing. So, if I have to say about one time, it's probably like a Friday night and I'm watching my movies, usually I'm wearing my pyjamas by then, - so yeah, had my pyjamas on, - and he sits down on the couch...

What is evident from this account is that it has been reconstructed from what the child knows typically happens. Attentive interviewers will notice the generic language (e.g., present tense; terms like "usually"). When people retrieve script information, memory for details that are always the same becomes strongest, and these are particularly resistant to suggestive or leading information (Connolly \& Lindsay, 2001; Gobbo, Mega \& Pipe, 2002). In contrast, details that vary across occurrences remain in memory but the associations between specific details and the occurrence in which they were present weakens, and this is especially true for 
children (Powell, Roberts, Ceci, \& Hembrooke, 1999; see Roberts, 2002, for a review). That is, when recalling a memory for which a script has been developed, children retrieve overall categories (e.g., whenever mum goes), and they have strong memories for the different alternatives (e.g., at work, at the neighbours, at the shops) associated with the categories (Roberts, 2002) but struggle in tying the alternatives to specific times (Lindsay \& Johnson, 1987). Interviewing, therefore, needs to be supportive in helping children to reconstruct these connections.

\section{Interviewing to Facilitate Retrieval of Individual Occurrences}

While existing interviewing guidelines (e.g., National Institutes of Child Health and Human Development [NICHD] Investigative Interview Protocol: Lamb, Orbach, Hershkowitz, Esplin, \& Horowitz, 2007; Stepwise Guidelines: Yuille, Cooper \& Hervé, 2009) do include important information regarding questioning about multiple incidents, the breadth and complexity of this issue necessitates further treatment and more elaborated strategies. Interviewers have also expressed extra challenges in helping children talk about individual incidents of repeated events (Powell, Roberts, \& Guadagno, 2007; Roberts \& Cameron, 2004). There is now a sufficient body of research conducted over the past two decades (e.g., Connolly \& Lindsay, 2001;

Connolly \& Price, 2006; Drohan-Jennings, Roberts \& Powell, 2010; Farrar \& Boyer-Pennington, 1999; Farrar \& Goodman, 1992; Odegard, Cooper, Lampinen, Reyna \& Brainerd, 2009; Pearse, Powell \& Thomson, 2003, Powell et al., 1999; Powell, Roberts, Thomson \& Ceci, 2007; Powell \& Thomson, 1996; 1997; 2003; Powell, Thomson \& Dietze, 1997; Roberts \& Powell, 2005; 2006 ; 2007) to solidify our understanding of children's memories for repeated events so that we can begin to make evidence-based recommendations for practice. 
We now discuss the specific cognitive tasks in which children must engage in order to retrieve and report individual occurrences of repeated events, the research aimed at understanding how children undertake these tasks, and the theoretically-guided interviewing procedures that facilitate them. The techniques we present are not meant as a replacement to existing best practice interviews, but instead to serve as specialized considerations in cases of repeated allegations. As such, we omit discussion of basic best-practice guidelines for the interviewing of all children, such as delivery of 'ground rules', eliciting a disclosure, the option of including a break during the interview, closure, and so on. For a more in-depth examination of widely-held current views on interviewing children, we refer the reader to Lamb, La Rooy, Malloy and Katz (2011).

Enhancing awareness of the relevance of individual occurrences. The investigative interview situation is an unusual interaction for children (Saywitz, Esplin, \& Romanoff, 2007), who are more accustomed to being asked questions by informed adults who already know the answers, than being the sole informants of their experiences (Poole \& Lamb, 1998). A Narrative Practice phase (also sometimes referred to as Episodic Memory Training, e.g., Lamb et al., 2007) is widely included in interviewing guidelines around the world (e.g., NICHD protocol, Stepwise guidelines). Engaging in practice gives the child the opportunity to be the 'expert' in responding to open questions with sufficient detail and has been shown to increase the amount (Sternberg et al., 1997; Sternberg, Lamb, Orbach, Esplin, \& Mitchell, 2001) and accuracy (Roberts, Lamb, \& Sternberg, 2004; Saywitz, Geiselman, \& Bornstein, 1992; Saywitz \& Snyder, 1996; Whiting, 2013) of information in children's narrative responses, at least for children who are verbally competent. It also has the added benefit of building rapport (Price, Roberts, \& Collins, 2013; see Roberts, Brubacher, Powell, \& Price, 2011, for a review). Prior to broaching substantive issues, 
interviewers should spend a few minutes engaging children in recall of events unrelated to the abuse.

The Practice Phase also benefits interviewers by giving them time to become familiar with a child's linguistic capabilities and to themselves practice asking episodic questions which they will do later in the interview when asking children to describe specific occurrences (Roberts et al., 2011). For example, Brubacher, Roberts, and Powell (2011) found that when interviewers asked episodic questions of 5- to 8-year-old children in practice (and children responded episodically), children with repeated experience of a classroom event went on to describe occurrences of the classroom event more episodically than children who answered general (generic) questions in practice (e.g., what usually happens when the child goes to swimming lessons/grandma's, etc.). Further, some children in Brubacher et al.'s (2011) study were asked to practice talking about two occurrences of a repeated autobiographical event (e.g., the last time at swimming lessons and another time), while other children only practiced talking about a singleexperience event The Practice Phase lasted approximately 5 to 7 minutes for all children, regardless of type of event practiced. The 5- and 6-year old children who practiced two occurrences: 1) reported more information overall about the classroom events; 2) spontaneously mentioned more distinct details or differences across occurrences; and 3) spontaneously told the interviewer that the classroom events happened more than once much earlier in the interview, compared to 5- and 6-year olds who practiced talking about a single experience and those who practiced responding to generic prompts.

The researchers concluded that practice in describing two incidents of repeated events heightened the children's awareness that the separate occurrences of the classroom events were relevant for discussion. Older children who participated in the study (7- and 8-year-olds) 
benefitted from episodic practice of both repeated and single events (versus generic practice), as they better understood requests to describe specific occurrences of the events. Additionally, a control group of children only participated one time; their reports were unaffected by the type of practice in which they engaged thus showing that repeated-event practice does not make children more suggestible regarding whether the abuse was repeated or not. These findings are very important for field interviews when the frequency of allegations may be unknown or ambiguous.

The bottom line: Before talking about allegations of abuse, a Practice Phase should be conducted. We recommend that children practice describing two occurrences of a repeated event because it promotes children's awareness that occurrences of a repeated event should be described in specific detail, and that occurrences which seem very similar do contain distinctive information (i.e., differences). No negative effects of practicing two occurrences were found by Brubacher and colleagues (2011), and the principle that practiced skills translate to behaviour in the substantive phase is supported by existing memory practice literature (i.e., Roberts et al., 2004; Saywitz et al., 1992; Saywitz \& Snyder, 1996; Sternberg et al., 1997; 2001).

Episodic memory training of two occurrences of a repeated event prepares children to: 1) recall an occurrence that can be distinguished from the generic script of 'what usually happens' by retrieving unique features (e.g., forgetting one's towel, having a different teacher than usual); and then 2) evoke the specific details related to that feature (e.g., "well... I forgot my towel but we got snacks at the end and so I dried off in the sun, and we played a ball game in the water with a new beach ball"). Importantly, practice in talking about two occurrences need not take more time than practice of just one event. Front-line interviewers often express concern that engaging in practice will add minutes to the interview (see Roberts et al., 2011) but a field study has demonstrated that interviews with a practice phase were in fact no longer than interviews 
without (Price et al., 2009; see also Saywitz et al., 1992), presumably because children who were practiced in responding to open-ended questions provided more informative responses and thus required fewer questions (Sternberg et al., 1997; 2001).

Finally, practice in describing two occurrences permits children to receive modelling in labelling the occurrences ("ok, let's call that the time you forgot your towel"); the benefits of labels are discussed in more detail later in this paper. Consider the following excerpts from a Practice Phase that includes practice of two occurrences of a repeated event and an example of labelling:

First Occurrence

I: So, you told me you go to drama lessons each week. Tell me all about the last time you went to drama lessons.

C: Last week,.. we, um, in the last time we started to get ready for our new-, because every few weeks we change and do a new play or show, so our teacher said 'it's time to think about what we want to do' and we said we wanted to do an outer-space one. I: Ok, tell me more about that.

$\mathrm{C}$ : We-, so, my friend $\mathrm{J}$ had an idea about being an alien who needed to get, to find something. She wanted to make her costume from this big box she had at home. The teacher-, Ms. R, she asked the rest of us to come up with parts of the story... [truncated].

\section{Second Occurrence}

I: Ok, tell me about another time you went to drama lessons. C: Well, they're kind of all the same, we just do drama stuff.

I: That's ok, I'd still like to hear all about another time.

C: Um, well, another time was, uh, we had a party a few weeks ago after we did our oper-, operetta.

I: Ok, let's call that the time you had the party. Tell me what happened at drama lessons the time you had the party. [Labelling the second occurrence].

C: Mmm, well, we could all bring our parents and-, or who, anybody who we wanted and we all had to bring some food, and mum made me some carrot cakes to take. And so, before we started the party we had to put on these little, like-, these little skits just out of our heads, and then [truncated]

I: Tell me more about the skits you did, the time you had the party. 
Observe that the interviewer uses open-ended prompts that refer to specific occurrences of the child's drama lessons. Because such strong scripts exist for highly familiar events children may protest that each time is "the same", but they should be encouraged to describe another time because, as shown above, children are able to find unique details in a repeated event. This is key to giving them practice in recognizing that individual occurrences of repeated events are not identical and that the interviewer wants to hear about each one in detail (see Roberts et al., 2011). The second occurrence discussed in practice should be given a label to distinguish it from the first. Note that it does not necessarily matter if there were any other times at drama lessons where there was a party, but that the two occurrences discussed can be distinguished from one another. The goal of Practice is to talk about two occurrences of a repeated event; not all of the occurrences of that event the child can remember.

Talking about the frequency and timing of abusive occurrences. Children must report how often the abuse, or specific types of abuse, occurred; at least whether it was a single or multiple offence in order to determine appropriate charges and to provide adequate protection for the child. Although it would be ideal for children to report information about the frequency of allegations spontaneously (which they are more apt to do following episodic practice of two occurrences of repeated events; Brubacher et al., 2011), not all children may do so. For example, the children in Brubacher and colleagues' (2011) study who practiced describing a singleexperience event responded episodically to interviewer prompts to describe an occurrence of the repeated classroom event, but most had to be asked later in the interview whether they had participated one time or more than one time. Despite having provided an account that sounded like a single episode, these children with repeated classroom experience accurately replied that they had participated more than once. 
In one of the most highly-regarded protocols, the NICHD protocol, it is recommended that children be asked about event frequency early on in the interview, in the format "did X happen one time or more than one time?" and not to be asked for specific numbers or to make evaluative judgements (e.g., "was it a lot?”) (Lamb et al, 2007; Orbach \& Pipe, 2011). When describing frequency, time and duration, young children frequently use words that they do not fully understand (see Lamb, Malloy, Hershkowitz, \& Malloy, in press; Poole \& Lamb, 1998, for reviews), they respond inconsistently (Friedman, Gardiner, \& Zubin, 1995), and they tend to underestimate frequency (e.g., Ellis, Palmer, \& Reeves, 1988). The development of counting skills for concrete objects (e.g., toy blocks) precedes the ability to count occurrences from memory and so counting skills should not be taken as evidence of aptitude to estimate abstract number concepts (Walker, 1999). Thus, asking children to provide information beyond their cognitive abilities can impair the credibility of their reports. Nevertheless, while children with repeated experience are poor at providing a specific estimates of frequency (Sharman, Powell, \& Roberts, 2011; Wandrey, Lyon, Quas, \& Friedman, 2012), research has also demonstrated that they are sensitive to frequency; their estimates increase as the number of experiences increases (e.g., Connolly, Hockley \& Pratt, 1996), thus they are likely to be accurate when responding "more than one time" even if the exact frequency is unavailable to them. In line with recommendations from other experts, we endorse the use of the "one time or more than one time?" prompt, which can also be used later in the interview as needed (e.g., to find out if specific abusive acts have occurred repeatedly; e.g., "Has he put his hand in your shirt one time or more than one time?").

Sometimes interviewers will wish to locate specific occurrences of abuse in time. Children below the age of around 7- to 8-years old have limited ability to aid in this respect although they 
can be informative in certain circumstances. For example, as young as 4-years of age, children can judge the relative recency of two events if both events were in the recent past (Friedman, 1991) but children as old as 10-years struggled to determine the order of two past annual events; they were unable to use their mental representations of the year to assist them in solving the problem (Friedman \& Lyon, 2005). As the delay between the event and the point at which children are asked to judge its temporal location lengthens, the age at which children can respond accurately also increases (Friedman, 1991; Friedman \& Lyon, 2005). Just as in questioning children about relative (rather than precise) estimates of frequency, interviewers must be aware that temporal information from children tends to approximate rather than specify, but these approximations tend to fall close to the actual date (see also Friedman, Reese, \& Dai, 2011). For example, between the ages of 6- to 9-years old, interviewers can expect children to specify the season in which an event occurred at levels above chance (Friedman, 1991; Friedman \& Lyon, 2005).

Describing individual occurrences. Arguably the most important task the child faces in cases where particularization is required is to describe individual occurrences of abuse with enough detail that it can be understood what has happened, and with specific details accurately ascribed to the occurrence in which they were in fact present. Accurately attributing details to specific occurrences involves a decision-making process known as "source monitoring" (see Johnson, Hashtroudi, \& Lindsay, 1993). The source-monitoring framework suggests that, when trying to determine the origin of a memory (e.g., "I remember biting him once [memory] - was that the time in the tent, or was it when we were in the basement - or did I just imagine that [three possible origins]?"), people evaluate the characteristics of those memories and make decisions based on the perceptual and cognitive features of those characteristics. Considering the 
previous example, a child may recall that the suspect cried out in pain when she bit him, and on the basis of that perceptual experience, she rejects the notion that she just imagined it. She may then recall that the suspect pushed her away and she fell on her sleeping bag, in which case she reasons that the correct occurrence must have been the time in the tent.

The ability to make source decisions improves with age, with the greatest gains between 3 and 8 years (see Foley, 2014; Roberts, 2002 for reviews) but the possibility of making a source error can occur at any age. Source errors can include confusing actual experiences with events seen on TV, overheard, or read about, as well as confusing occurrences of a repeated event (Roberts, 2002). The more similar the sources, the more difficult the judgement (Lindsay, Johnson, \& Kwon, 1991). The most common source error made by children following repeated experience is reporting things that truly happened but making confusions about the 'when' (i.e., mixing up details across occurrences; Powell et al., 1999) because the temporal source of the memory becomes disassociated from the content of the events (Friedman et al., 2011; Powell \& Thomson, 1997) Thus, children with repeated experience describe their memories of what happened over a time frame accurately, but cannot confidently say which details go with which incidents.

\section{Recommendations for Forensic Practice}

In the following four sub-sections of this paper we discuss theoretically- and empiricallyguided techniques that are likely to support children's narratives in terms of the amount of specific detail they provide about occurrences of repeated events, their accuracy in attributing that detail to individual occurrences, or both. In addition, some of these techniques may also facilitate retrieval of generic information that can help to provide a more comprehensive picture of the child's overall experiences. 
(1) Delivering open-ended prompts. Eliciting the majority of information from children using open-ended prompts (e.g., "Tell me about X") is known to yield more complete and/or more accurate accounts than asking specific closed questions (Dent \& Stephenson, 1979; Lamb, 1996; Orbach \& Pipe, 2011; Poole \& Lindsay, 1995). This recommendation is not unique to asking children about repeated experience but it is so fundamental to good interviewing that it bears inclusion here. In addition, as we will show, there are extra challenges associated with posing questions to children with repeated experience. It is now well-understood that conducting the interview in an open-ended manner increases the likelihood that coherent information with episodic narrative quality will be reported (Feltis, Powell, Snow \& Hughes-Scholes, 2010). When allowed to provide a free-narrative account, children 4 to 10 years old spontaneously provide temporal information (with age-related increases in doing so; Orbach \& Lamb, 2007) that can be helpful in pinning down the time frame and duration of occurrences, lessening the need to ask specific questions. In a focus-group study conducted by Powell, Wright, and HughesScholes (2011), a child-testimony expert made the following statement about a forensic interview with a young child:

Interviewers are more likely to get accurate details in a free narrative account than in response to specific questions about time and place. If she [the child] had been encouraged to provide more elaborate details with minimal prompting, she might have disclosed information that would have helped to clarify the time of the offence. (p. 34)

Highly specific questions should be avoided when interviewing children but they may be especially detrimental in cases of repeated allegations because, for reasons discussed earlier, children's memories for the content of repeated experiences are very strong but the sources (occurrences) become confused. For example, "the time he tried to kiss you, was he wearing his 
pyjamas or the black $t$-shirt?"(italics represent details already mentioned by the child) requires the child to make a source judgement and due to the repeated nature of events, it may be the case that there were several times the suspect tried to kiss the child and both options may be correct (see Guadagno \& Powell, 2009).

Open-ended prompts are only successful, however, when they do not include suggested detail (Powell \& Snow, 2007; see Sharman \& Powell, 2012, for an illustration of how openended questions containing misleading content can affect adults' memory). Not only can questions be suggestive with regards to the content ("what happened when he took off his tshirt?" when the child only stated that the suspect took off his clothes and made no reference to a shirt), they can also be suggestive about the temporal components, a critical concern when interviewing about repeated events (e.g., "tell me what happened when he took off his shirt the time he tried to kiss you" when both elements are true but they were not the same occurrence); see Powell et al. (2007) for evidence that children are more likely to falsely acquiesce to suggestions about details that happened but not in a target occurrence, relative to details that never happened at all. Further, children are more likely to accept suggested content details when they have been linked to a specific occurrence (e.g., "so when he kissed you in the tent... ") than when not (e.g., "so when he kissed you...") (Powell, Roberts, \& Thomson, 2000).

The utility of non-leading open-prompts in eliciting relevant details has been shown to extend through the interview (i.e., beyond the initial invitation), for both younger and older children (i.e., 4- to 8-year-olds; e.g., Hershkowitz, 2001), although note that some recent evidence suggests that children 4-years old and younger respond slightly more informatively to direct recall prompts than to open-ended prompts (Hershkowitz, Lamb, Orbach, Katz, \& Horowitz, 2012). Whilst it is often expressed that the youngest children provide the least 
information in response to open-ended prompts, they also make the most commission errors in response to forced choice or leading questions (see Olafson, 2006 for a review). If there is any need to ask closed-ended questions, we recommend that these be asked at the end of the interview after all raised occurrences were probed with recall questions (i.e., open, and direct when necessary; see Lamb et al., 2007, p. 1224 - 1225). Interviewers should keep in mind, however, that some specific information (e.g., temporal details such as the dates of a summer holiday when the alleged abuse occurred) can be asked of non-offending caregivers (Powell \& McMeeken, 1998).

(2) Permitting an initial generic account. Although prompting for episodic information is critical for particularization, interviewers should be aware that generic detail can sometimes be informative (see Tully, 2011). Children as young as 3-years of age have scripts for highly routine events (Nelson, 1986; Nelson \& Gruendel, 1981), and even pre-verbal children (less than 12 months) can accurately remember action sequences for familiar events (Bauer \& Mandler, 1992). Our natural recall of experiences we have had on multiple occasions is typically a mix of episodic and generic information (Farrar \& Boyer-Pennington, 1999; Hudson et al., 1992) and so generic scripts can contain references not only to what is always the same, but also to what details typically change or are unique to particular times (Brubacher et al., 2011; Brubacher, Roberts, \& Powell, 2012). Indeed, memory models suggest that a close relationship exists between the event script and specific episodic occurrences (Reiser, Black \& Abelson, 1985). That is, individual occurrences are represented hierarchically within the script, with mental 'tags' pointing to script-atypical details (Graesser, Gordon, \& Sawyer, 1979). Activation of the memory script thus leads to reactivation of the atypical details (Reiser et al., 1985). In other words, thinking about "what usually happens" also leads to recall of what sometimes changes or 
an unexpected happenstance. Consider the child's statement below, which immediately followed the generic account we presented earlier:

C: oh, but this one time I remember he just started, like, he had the zip down on his jeans, and it was nearly my bedtime - just about 9 , and the neighbor came at the door. He jumped up like, just, like 'I wasn't doing anything' and quickly went to cause, we were right in the lounge room that's right by the window at the front door, so he zipped up quickly and answered the door. When the neighbor went, he just did the things he normally does but a bit less- yeah, because it was, he had less time before mum got home.

Recent research has indeed demonstrated that allowing children to report their scripts before describing individual instances may confer benefits on their narratives for the individual instances. Brubacher et al. (2012) asked half of the 4- to 8-year old children who had participated in a series of repeated classroom events to first talk about "what usually happens" at the Activities, and the other half of children were first asked to describe the "time you remember best." After recall was exhausted, all children were then given the alternate prompt. Results showed that children who first talked about what usually happened reported more information overall, and mentioned more differences across occurrences, than did children who talked about a specific time first, without corresponding decreases in accuracy. This finding was replicated by Connolly and Gordon (2011) who involved children in additional participation sessions (up to six events) thereby strengthening the event script. Additionally, in Brubacher and colleagues' (2012) study, engaging first in generic recall did not lead to increased reporting of script memories when subsequently questioned about a specific occurrence, relative to children who described an occurrence first. That is, even though the children were allowed to first give their event script, they later complied with prompts to describe specific occurrences.

A similar investigation (Brubacher, 2011) also demonstrated positive effects of recalling the script first. In this latter study, there were no differences in the amount of details reported, 
but children who described what usually happens first were more accurate for the details that were different across occurrences than children who described an incident first. There were differences in the structure of the participatory repeated events that likely underlie the slightly discrepant results, but both experiments concluded that allowing children to report scripts first can yield benefits.

These data do not suggest, however, that interviewers should abandon episodic prompts. On the contrary; we know that episodic prompts are very likely to elicit the episodic responses (Brubacher et al., 2011; 2012; Schneider, Price, Roberts, \& Hedrick, 2011) necessary for particularization. But some children, especially following prolonged abuse, may have initial difficulty in describing specific episodes of their experiences (Terr, 1990; 1994; Williams, 1996). If the event script is more memorable, and/or if children feel more comfortable reporting generic details, they should be permitted to report that information first and it does not mean that occurrences will not be particularized. This suggestion is concordant with the vast body of research suggesting that the memory search by interviewees should commence in as unrestricted a manner as possible: that is, the underlying cognitive principles of asking open-ended rather than specific prompts (e.g., Powell \& Snow, 2007) and encouraging interviewees to 'report everything' (Memon \& Higham, 1999).

The various 'episodic leads' that may arise during script recall can be used by the interviewer as labels (i.e., specific words referring to occurrences) once generic recall has been exhausted. This process enhances the likelihood that interviewers can follow up on these occurrences one at a time (as is recommended; Guadagno \& Powell, 2009), reducing the need to 'jump around' between occurrences during the interview. Switching back and forth between occurrences is known to interfere with memory recall (Smith \& Milne, 2011). Sometimes 
switches are initiated by the child, but the interviewer's role will be to refocus the child's attention on the occurrence at hand (Brubacher, Malloy, Lamb, \& Roberts, 2013). From a prosecutor's perspective, if the child's interview is being used as evidence-in-chief, an interview where information from several episodes is intermingled is likely to be long and confusing to listen to, and courts may not want to use it in proceedings (Burrows \& Powell, 2013; Smith \& Milne, 2011). Finally, eliciting episodes one at a time will produce a more coherent, narrative account, which has positive effects on perceptions of children's credibility (Davis et al., 1999).

Allowing children to report their scripts before talking about specific episodes - if the children are so inclined to do - has benefits in producing labels for individual occurrences and the overall organization of their episodic reports, but is also useful in jurisdictions that do not have a particularization requirement because it allows for a large amount of information to be provided and a general picture of the maltreatment (see also the "Whole Story Approach"; Tidmarsh, Powell, \& Darwinkel, 2012). In summary, we recommend that interviewers reflect the language of the child's initial disclosure. That is, if the child's initial narrative includes generic information (e.g., "Uncle B's been doing bad things"), the interviewer's next prompt should follow the same format (e.g., "tell me about the bad things [Uncle B has been doing]"). Below we provide a few examples of generic prompts that will be helpful in eliciting the abuse script.

I: What else happens [has happened]?

I: Tell me more/tell me everything about when he plays the naughty game with you.

I: You said Uncle B has been touching you; tell me more about when he touches you. I: You said 'when mum goes out'. Tell me what happens when mum goes out. I: You said he does it 'just like normal'; tell me more about that.

(3) Adopting children's labels or using their words to create labels. Allowing children to report their script first increases the potential that they will report details specific to individual 
occurrences (e.g., "once he even did it when mum was just asleep downstairs"); we have previously referred to these as 'episodic leads'. These can then be used by the interviewer to explicitly label the occurrence(s) they wish to discuss (e.g., "tell me about the time when mum was just asleep downstairs") (see Reiser et al., 1985, for a discussion of how recalled details can lead to an effective mental search for specific episodes to which the details are linked). The risk of confusion is lower when children themselves label occurrences because children are the ones with the access to information; if they provide labels or episodic leads, there is at least the potential that they are unique to one occurrence, whereas an interviewer has only the child's description of what happened/happens. Children are capable of choosing unique labels and/or reporting information that is unique to specific times (even if they do not use it in an explicitly labelling manner such as "the time when") (Brubacher, Glisic, Roberts \& Powell, 2011; Hudson, 1988).

Some children may not spontaneously provide a label for each occurrence they are describing, and thus the interviewer must take the lead in doing so. We recommend that, in these circumstances, interviewers use the child's own words to designate a label, reflecting on episodic leads that have arisen in the course of the child's narrative. The distinction we make between labels and episodic leads is in the manner they are used. Labels are signified by "the time/day/occasion when", whereas episodic leads are not. Consider the narrative from the child whose abuse was interrupted: "this one time I remember he just started, like, he had the zip down on his jeans, and it was nearly my bedtime - just about 9 , and the neighbor came at the door". In this example, there is no clear label, but an interviewer can use the child's words to say "tell me about the time when the neighbor came at the door." 
Labels can be temporal terms (e.g., the last time), or they can be words that refer to an element of the context, such as the location (e.g., "time in the tent"), a specific type of abuse (e.g., "the time he put his hand inside your pants"), or other situational element (e.g., "the time mum was at the shops"). See Pearse and colleagues (2003) for further discussion regarding the use of contextual cues as labels. In addition, labels should be made explicit (i.e., "let's call that the time X") as this will reduce confusion when the child or interviewer wants to return to a discussion of a particular time (Powell et al., 2007a). Unique labels are extremely useful to help differentiate occurrences (Orbach \& Pipe, 2011). If it becomes apparent that the chosen label is not unique (e.g., the neighbor has interrupted several times) the label may require modification (e.g," "ok, so we're talking about the time that happened just last week when the neighbor came at the door").

If a child did not provide any unique information during the generic account, interviewers may ask if anything different ever took place (e.g., "Was there [ever] a time when something different happened?"). Currently no published research exists to support asking about differences in this manner, but raw data from the authors' labs suggests that it can sometimes result in new episodic leads, and research on children's memory for script-atypical details also supports the potential usefulness of this question (e.g., Hudson, 1988; Davidson \& Hoe, 1993). Another strategy interviewers should consider, especially if the child has not spontaneously mentioned any specific episodes, is to ask about the first and last time because there is evidence to suggest that children 6-years and older will have stronger memories for these than other occurrences due to primacy and recency effects (Powell, Thomson, \& Ceci, 2003). Existing guidelines also encourage asking about these times (e.g., Lamb et al., 2007). 
Recent research demonstrates that children are informative when asked whether their labels are unique (e.g., "did [label] happen any other time?”; Brubacher, Roberts \& Powell, 2011). Indeed, in that study, $98 \%$ of the children produced a unique label (with or without the assistance of the interviewer) for the occurrence of the repeated classroom event that they described. Thus, clarifying the uniqueness of a label appears to be a worthwhile endeavour. Below we revisit the narrative from the child we met earlier, and show how the interviewer made use of the techniques described in this section.

C: oh, but this one time I remember he just started, like, he had the zip down on his jeans, and it was nearly my bedtime - just about 9, and the neighbor came at the door. He jumped up like, just, like 'I wasn't doing anything' and quickly went to cause, we were right in the lounge room what's right by the window at the front door, so he zipped up quickly and answered the door. When the neighbor went, he just did the things he normally does but a bit less- yeah, because it was, he had less time before mum got home.

\section{a) Use the child's episodic leads to create labels and make labels explicit:}

I: Ok, thank you for telling me about that. I'd like to talk about that time you just mentioned, let's call that the time the neighbor came at the door. Tell me everything that happened that time when the neighbour came at the door ...

C: Well, it just started out as normal, so as I've said he-, I was watching my, uh, ok, that time I was watching a television show, it was Glee, and he came in the room and sat beside me on the couch. He said 'what are you watching?' and I just said it was my program like-, sort of trying to ignore him, like

I: Ok

C: So, uh, so he started playing with the, um, with the button and zipper on his jeans. He-, sometimes he would get the blanket so that when, so nobody would see if they come to the door. So, he puts that over him, and over me, just-, over our legs. And then he just does it.

b) When unsure, ask if labels are unique:

I: Ok, were there any other times when the neighbor came at the door, when he did it?

C: Yeah, um, the neighbor comes sometimes when mum's at work, just to say hi and you know. I think the neighbor came a few times so he started putting the blanket over, but this time it was already so late-, like, it was almost 9 so my mum gets home at 9, so-, I don't think he thought anyone would be there. 
c) Adjusting labels for clarity:

I: Ok, so let's talk more about this time when the neighbor came and it was almost 9 [interview truncated].

d) Prompting for another occurrence after recall for the previous is exhausted:

\section{I: Can you tell me about another time?}

(4) Using the appropriate level of language specificity. Several analog and field studies now show that episodic prompts yield episodic responses from children, just as generic prompts yield generic responses (Brubacher et al., 2013; Brubacher et al., 2011; 2012; Schneider et al., 2011). Children are highly responsive to the language style of the interviewer. Throughout the interview, interviewers should be aware of the level of specificity requested in their prompts. When episodic information is desired, it is necessary to communicate to the child the importance of reporting incident-specific information (Orbach \& Pipe, 2011). Thus when prompting for details of specific instances, interviewers should use past-tense, episodic prompts in contrast to generic prompts which can be reserved for the initial report. Below, we provide several examples of Episodic and Generic prompts:

\section{Episodic prompts}

"Tell me what happened that time"

"You said 'he got on the bed'. Then what happened?"

"What else happened, the time mum was at the shops?"

"Ok, you said there was a time he grabbed you in the shed. Tell me everything that happened"

\section{Generic prompts}

"Tell me what happens"“You said 'he gets on the bed.' Then what happens?"

"What else happens, when mum's gone out?"

"Ok, you said you've been in the shed with him a few times. Tell me what happens."

\section{Considerations for Implementation}


The techniques presented in this paper are grounded in scientific research concerning children's memory development and organization of repeated events, and should facilitate as much as possible children's reports of both individual incidents of sexual abuse and a comprehensive account of the ongoing abuse as a whole. They can be combined with any existing best-practice guidelines as they expand upon the information already contained in those procedures. Nevertheless, we caution investigators that the majority of foundational research reviewed herein was conducted in analogue laboratory settings. There may be as of yet unknown risks associated with using these techniques in the field, and researchers will continue to evaluate these procedures as they begin to be employed in front-line interviews. Despite this caveat, there is now strong empirical evidence to suggest that the procedures and techniques we have discussed will confer benefits on children's narrative reports of repeated experiences.

Our focus in this paper has been on interviewing children making allegations of repeated sexual abuse because in such cases children are often the only witnesses to their experiences, making their testimony especially important for prosecution. Nevertheless, child physical abuse is also frequently a repeated crime (e.g., Finkelhor, Hotaling, Lewis, \& Smith, 1990;

Hershkowitz \& Elul, 1999) and the techniques we described may be appropriate in these cases as well; however, this assumption has not yet been tested.

\section{Conclusion}

In summary, right from the beginning of the interview in the narrative practice phase, interviewers can demonstrate to the child that individual occurrences of repeated events are important for discussion by delivering open-ended, episodic prompts to elicit accounts of two occurrences of an autobiographical repeated event. This procedure has the added benefit of increasing the likelihood that children will spontaneously reveal the repeated nature of their 
abuse allegations (if indeed it was repeated) and does not increase false claims of repeated experience by children who have a single abusive experience. Nevertheless, some children may require questioning about abuse frequency and, in line with established guidelines, we too recommend that all questions about frequency are asked in the format "one time or more than one time?" Although we advocate episodic practice we also suggest that interviewers allow children to make an initial generic report of their abuse if a given child seems inclined to do so. This generic account of "what usually happens" can in fact be rich in episodic information specific to individual occurrences (e.g., "but one time x happened instead because...") and provides a broader picture of what the child has experienced.

Once generic recall is exhausted, we advise interviewers to prompt children episodically to describe individual occurrences one at a time using the child's own words as labels (e.g., "ok, tell me about the time $\mathrm{x}$ happened"). Throughout the conversation, interviewers should be aware of the level of language specificity they and the child are using (i.e., episodic language is generally indicated by use of the past-tense, while generic language tends to be signified by present-tense), and moderate their usage depending upon the type of information they wish to elicit. The research we have reviewed here suggests that these techniques should improve interviewers' ability to aid children in reporting individual occurrences in jurisdictions where particularization is compulsory, and are similarly useful for enhancing the clarity and credibility of children's accounts even where not required. 


\section{References}

Abelson, R. P. (1981). Psychological status of the script concept. American Psychologist, 36, 715-729. doi: 10.1037/0003-066X.36.7.715

Bauer, P. J., \& Mandler, J. M. (1992). Putting the horse before the cart: The use of temporal order in recall of events by one-year-old children. Developmental Psychology, 28, 441 452. doi: $10.1037 / 0012-1649.28 .3 .441$

Brubacher, S. P. (2011). Understanding children's representation and recall of individual occurrences of repeated events. Waterloo, Canada: Wilfrid Laurier University (Doctoral dissertation).

Brubacher, S. P., Glisic, U., Roberts, K. P., \& Powell, M. B. (2011). Children's ability to recall unique aspects of one occurrence of a repeated event. Applied Cognitive Psychology, 25, 351 - 358. doi: 10.1002/acp.1696

Brubacher, S. P., Malloy, L. C., Lamb, M. E., \& Roberts, K. P. (2013). How do interviewers and children discuss individual occurrences of alleged repeated abuse in forensic interviews? Applied Cognitive Psychology, 27, 443 - 450. doi: 10.1002/acp.2920

Brubacher, S. P, Roberts, K. P., \& Powell, M. B. (2011, March). Training children with repeatedevent experience to label unique aspects of occurrences. Paper presented in L. C. Malloy (Chair), Motivational and cognitive influences on children's testimony. Symposium at the annual meeting of the American Psychology-Law Society $/ 4^{\text {th }}$ International Congress on Psychology and Law, Miami, FL.

Brubacher, S. P., Roberts, K.P., \& Powell, M. (2011). Effects of practicing episodic versus scripted recall on children's subsequent narratives of a repeated event. Psychology, Public Policy, and Law, 17, 286-314. doi: 10.1037/a0022793 
Brubacher, S. P., Roberts, K. P., \& Powell, M. B. (2012). Retrieval of episodic versus generic information: Does the order of recall affect the amount and accuracy of details reported by children about repeated events? Developmental Psychology, 48, 111-122. doi: $10.1037 / \mathrm{a} 0025864$

Burrows, K. S., \& Powell, M. B. (2013). Prosecutors' recommendations for improving child witness statements about sexual abuse. Policing and Society: An International Journal of Research and Policy. Advance online publication 9 April, 2013. doi:10.1080/10439463.2013.784305

Connolly, D. A., \& Gordon, H. M. (2011, June). General and specific memory for repeated events: Does it matter which is prompted first? Paper presented at the $9^{\text {th }}$ biennial meeting of the Society for Applied Research in Memory and Cognition, New York, NY.

Connolly, D. A., Hockley, W. E., \& Pratt, M. W. (1996). A developmental evaluation of frequency memory for actions presented in lists, scripts, and stories. Memory, 4, 243-263. doi: $10.1080 / 096582196388942$

Connolly, D. A., \& Lindsay, D. S. (2001). The influence of suggestions on children's reports of a unique experience versus an instance of a repeated experience. Applied Cognitive Psychology, 15, 205-223. doi: 10.1002/1099-0720(200103/04)15:2<205::AIDACP698>3.0.CO;2-F

Connolly, D. A., \& Price, H. L. (2006). Children's suggestibility for an instance of a repeated event versus a unique event: The degree of association between variable details. Journal of Experimental Child Psychology, 93, 207 - 223. doi: 10.1016/j.jecp.2005.06.004 
Connolly, D. A., \& Read, J. D. (2006). Delayed prosecutions of historic child sexual abuse: Analyses of 2064 Canadian criminal complaints. Law and Human Behavior, 30, 409 434. doi: 10.1007/s10979-006-9011-6

Davidson, D., \& Hoe, S. (1993). Children's recall and recognition memory for typical and atypical actions in script-based stories. Journal of Experimental Child Psychology, 55, 104-126. doi: 10.1006/jecp.1993.1005

Davis, G., Hoyano, L., Keenan, C., Maitland, L., \& Morgan, R. (1999). An assessment of the admissibility and sufficiency of evidence in child abuse prosecutions. London, UK: Home Office.

Dent, H. R., \& Stephenson, G. M. (1979). An experimental study on the effectiveness of different techniques of questioning child witnesses. British Journal of Social \& Clinical Psychology, 18, 41-51. doi: 10.1111/j.2044-8260.1979.tb00302.x

Drohan-Jennings, D. M., Roberts, K. P., \& Powell, M. B. (2010). Mental context reinstatement increases resistance to false suggestions after children have experienced a repeated event. Psychiatry, Psychology and Law, 17, 594-606. doi: 10.1080/13218711003739110

Ellis, N. R., Palmer, R. L., \& Reeves, C. L. (1988). Developmental and intellectual differences in frequency processing. Developmental Psychology, 24, 38 - 45. doi: 10.1037/00121649.24.1.38

Farrar, M. J., \& Boyer-Pennington, M. E. (1999). Remembering specific episodes of a scripted event. Journal of Experimental Child Psychology, 73, 266-288. doi:10.1006/jecp.1999.2507

Farrar, M. J., \& Goodman, G. S. (1992). Developmental changes in event memory. Child Development, 63, 173-187. doi: 10.2307/1130911 
Feltis, B. B., Powell, M. B., Snow, P. C., \& Hughes-Scholes, C. (2010). An examination of the association between interviewer question type and story-grammar detail in child witness interviews about abuse. Child Abuse \& Neglect, 34, 407-413. doi:

10.1016/j.chiabu.2009.09.019

Finkelhor, D. (1979). Sexually victimized children. New York, NY: Simon \& Schuster.

Foley, M. A. (2014). Children's Memory for Source. In P. J. Bauer \& R. Fivush (Eds.), The Wiley Handbook on the Development of Children's Memory, Volume I/II (pp. 427-452). Chichester, UK: Wiley

Friedman, W. J. (1991). The development of children's memory for the time of past events. Child Development, 62, 139 - 155. doi: 10.1111/j.1467-8624.1991.tb01520.x

Friedman, W. J., Gardner, A. C., \& Zubin, N. R. (1995). Children's comparisons of the recency of two events from the past year. Child Development, 66, 970 - 983. doi: 10.1111/j.14678624.1995.tb00916.x

Friedman, W. J., \& Lyon, T. D. (2005). Development of temporal-reconstructive abilities. Child Development, 76, 1202 - 1216. doi: 10.1111/j.1467-8624.2005.00845.x

Friedman, W. J., Reese, E. \& Dai, X. (2011). Children's memory for the times of events from the past years. Applied Cognitive Psychology, 25, 156 - 165. doi: 10.1002/acp.1656

Fivush, R. (1984). Learning about school: The development of kindergartners' school scripts. Child Development, 55, 1697 - 1709. Stable URL: http://www.jstor.org/stable/1129917

Gobbo, C., Mega, C., \& Pipe, M-E. (2002). Does the nature of the experience influence children's suggestibility? A study of children's event memory. Journal of Experimental Child Psychology, 81, 502 - 530. doi: 10.1006/jecp.2002.2662 
Graesser, A. C., Gordon, S. E., \& Sawyer, J. D. (1979). Recognition memory for typical tag + and atypical actions in scripted activities: Tests of a script pointer hypothesis. Journal of Verbal Learning \& Verbal Behavior, 18, 319 - 332. doi: 10.1016/S0022-5371(79)901828

Guadagno, B. L., Powell, M. B., \& Wright, R. (2006). Police officers' and legal professionals' perceptions regarding how children are, and should be, questioned about repeated abuse. Psychiatry, Psychology and Law, 13, 251 - 260. doi: 10.1375/pplt.13.2.251

Guadagno, B. L. \& Powell, M. B. (2009). A qualitative examination of police officers' questioning of children about repeated events. Police Practice \& Research: An International Journal, 10, 61 - 73. doi: 10.1080/15614260802128468

Hershkowitz, I. (2001). Children's responses to open-ended utterances in forensic interviews. Legal and Criminological Psychology, 6, 49 - 63. doi: 10.1348/135532501168190

Hershkowitz, I., Lamb, M. E., Orbach, Y., Katz, C., \& Horowitz, D. (2012). The development of communicative and narrative skills among preschoolers: Lessons from forensic interviews about child abuse. Child Development, 83, 611 - 622. doi: 10.1111/j.14678624.2011.01704.x

Hudson, J. A. (1988). Children's memory for atypical actions in script-based stories: Evidence for a disruption effect. Journal of Experimental Child Psychology, 46, 159 - 173. doi: $10.1016 / 0022-0965(88) 90055-0$

Hudson, J. A., Fivush, R., \& Kuebli, J. (1992). Scripts and episodes: The development of event memory. Applied Cognitive Psychology. Special Issue: Memory in everyday settings, 6, 483 - 505. doi: 10.1002/acp.2350060604 
Hudson, J. A., \& Mayhew, E. M. (2009). The development of memory for recurring events. In M. Courage \& N. Cowan (Eds.), The development of memory in infancy and childhood. (pp. 69 -92). New York, NY: Psychology Press.

Johnson, M. K., Hashtroudi, S., \& Lindsay, D. S. (1993). Source monitoring. Psychological Bulletin, 114, 3-28. doi: 10.1037/0033-2909.114.1.3

Lamb, M. E. (1996). Effects of investigative utterance types on Israeli children's responses. International Journal of Behavioral Development, 19, 627-638. doi: $10.1080 / 016502596385721$

Lamb, M. E., La Rooy, D. J., Malloy, L. C., \& Katz, C. (Eds.). (2011). Children's testimony: A handbook of psychological research and forensic practice. Chichester, UK: Wiley.

Lamb, Malloy, Hershkowitz, \& Malloy (in press). Children and the law. Chapter to appear in R. M. Lerner \& M. E. Lamb (Eds.), Handbook of child psychology and developmental science (7th edition), Vol. 3, Social, emotional and personality development. Hoboken, NJ: Wiley.

Lamb, M. E., Orbach, Y., Hershkowitz, I., Esplin, P. W., \& Horowitz, D. (2007). A structured forensic interview protocol improves the quality and informativeness of investigative interviews with children: A review of research using the NICHD investigative interview protocol. Child Abuse \& Neglect, 31, 1201 - 1231. doi: 10.1016/j.chiabu.2007.03.021

Lindsay, D. S., \& Johnson, M. K. (1987). Reality monitoring and suggestibility: Children's ability to discriminate among memories from different sources. In S. J. Ceci, M. P. Toglia, \& D. F. Ross (Eds.), Children's eyewitness memory (pp. 92 - 121). London, UK: Springer. 
Lindsay, D. S., Johnson, M. K., \& Kwon, P. (1991). Developmental changes in memory source monitoring. Journal of Experimental Child Psychology, 52, 297 - 318. doi: $10.1016 / 0022-0965(91) 90065-Z$

Memon, A., \& Higham, P. A. (1999). A review of the cognitive interview. Psychology, Crime and Law, 5, 177-196. doi: 10.1080/10683169908415000

Myles-Worsley, M., Cromer, C., \& Dodd, D. (1986). Children's preschool script reconstruction: Reliance on general knowledge as memory fades. Developmental Psychology, 22, $2-30$.

Nelson, K. (Ed.). (1986). Event knowledge: Structure and function in development. Hillsdale, NJ: Erlbaum.

Nelson, K., \& Gruendel, J. (1981). Generalized event representations: Basic Building Blocks of Cognitive Development. In M.E. Lamb \& A.L. Brown (Eds.), Advances in Developmental Psychology, Vol. 1 (pp. 131 - 158). Hillsdale, NJ: Erlbaum.

Odegard, T. N., Cooper, C. N., Lampinen, J. M., Reyna, V. F., \& Brainerd, C. J. (2009). Children's eyewitness memory for multiple real-life events. Child Development, 80, 1977 - 1890. doi: 10.1111/j.1467-8624.2009.01373.x

Olafson, E. (2006). Children's memory and suggestibility. In K. C. Faller (Ed.), Interviewing Children about Sexual Abuse: Controversies and Best Practice: Controversies and Best Practice (pp. 142 -151). New York, NY: Oxford University Press.

Orbach, Y., \& Pipe, M.-E. (2011). Investigating substantive issues. In M. E. Lamb, D. La Rooy, L.C. Malloy, \& C. Katz (Eds.), Children's testimony: A Handbook of psychological research and forensic practice (pp. 147-164). Chichester, UK: Wiley. 
Pearse, S. L., Powell, M. B., \& Thomson, D. M. (2003). The effect of contextual cues on children's ability to remember an occurrence of a repeated event. Legal and Criminological Psychology, 8, 39-50. doi: 10.1348/135532503762871228

Poole, D. A., \& Lamb, M. E. (1998). Investigative interviews of children: A guide for helping professionals. Washington, DC: American Psychological Association.

Poole, D. A., \& Lindsay, D. S. (1995). Interviewing preschoolers: Effects of nonsuggestive techniques, parental coaching, and leading questions on reports of nonexperienced events. Journal of Experimental Child Psychology, 60, 129-154. doi: 10.1006/jecp.1995.1035

Powell, M.B. \& McMeeken, L. (1998). “Tell me about the time when...”: 9 Golden Rules for interviewing a child about a multiple offence. Australian Police Journal, 52, $104-108$.

Powell, M.B., Roberts, K.P., Ceci, S.J., \& Hembrooke, H. (1999). The effects of repeated experience on children's suggestibility. Developmental Psychology, 35, 1462-1477. doi: $10.1037 / 0012-1649.35 .6 .1462$

Powell, M. B., Roberts, K.P., \& Guadagno, B. (2007a). Particularisation of child abuse offences: Common problems when interviewing child witnesses. Current Issues in Criminal Justice, 19, $64-74$.

Powell, M. B., Roberts, K. P., \& Thomson, D. M. (2000). The effect of a suggestive interview on children's memory of a repeated event: Does it matter whether suggestions are linked to a particular incident? Psychiatry, Psychology and Law, 7, 182 - 191. doi: $10.1080 / 13218710009524984$

Powell, M. B., Roberts, K. P., Thomson, D. M., \& Ceci, S. J. (2007b). The impact of experienced versus non-experienced suggestions on children's recall of repeated events. Applied Cognitive Psychology, 21, 649 - 667. doi: 10.1002/acp.1299 
Powell, M. B., \& Snow, P. C. (2007). Guide to questioning children during the free narrative phase of an investigative interview. Australian Psychologist, 42, 57 - 65. doi: $10.1080 / 00050060600976032$

Powell, M. B., \& Thomson, D. M. (1996). Children's memory of an occurrence of a repeated event: Effects of age, repetition, and retention interval across three question types. Child Development, 67, 1988 - 2004. doi: 10.2307/1131605

Powell, M. B., \& Thomson D. M. (1997). Contrasting memory for temporal-source and memory for content in children's discrimination of repeated events, Applied Cognitive Psychology 11, 339 - 360. doi: 10.1002/(SICI)1099-0720(199708)11:4<339::AIDACP460>3.0.CO;2-O

Powell, M. B., \& Thomson, D. M. (2003). Improving children's recall of an occurrence of a repeated event: Is it a matter of helping them to generate options? Law and Human Behavior, 27, 365 - 384. doi: 10.1023/A:1024032932556

Powell, M. B., Thomson, D. M., \& Ceci, S. J. (2003). Children's memory of recurring events: Is the first event always the best remembered? Applied Cognitive Psychology, 17, 127 146. doi: $10.1002 /$ acp. 864

Powell, M. B., Thomson, D. M., \& Dietze, P. (1997). Children's ability to remember an occurrence of a repeated event. Expert Evidence, 5, 133-139. doi: 10.1023/A:1008879019605

Powell, M.B., Wright, R., \& Hughes-Scholes, C.H. (2011). Contrasting the perceptions of child testimony experts, prosecutors and police officers regarding individual child abuse interviews. Psychiatry, Psychology and Law, 18, 33-43. doi:

$10.1080 / 13218710903566995$ 
Podirsky v. R. (1990). 3 WAR 128.

Price, H. L., Roberts, K. P., \& Collins, A. (2013). The quality of children's allegations of abuse in investigative interviews containing practice narratives. Journal of Applied Research in Memory and Cognition, 2, 1 - 6. doi: 10.1016/j.jarmac.2012.03.001

R. v. B. (G.) (1990). 2 S. C. R. 30.

Reiser, B. J., Black, J. B., \& Abelson, R. P. (1985). Knowledge structures in the organization and retrieval of autobiographical memories. Cognitive Psychology, 17, 89 - 137. doi: $10.1016 / 0010-0285(85) 90005-2$

Roberts, K. P. (2002). Children's ability to distinguish between memories from multiple sources: Implications for the quality and accuracy of eyewitness statements. Developmental Review, 22, 403-435. doi: 10.1016/S0273-2297(02)00005-9

Roberts, K. P., Brubacher, S. P., Powell, M. B., \& Price, H. L. (2011). Practice Narratives. In M.E. Lamb, D. La Rooy, L.C. Malloy, \& C. Katz (Eds.), Children's testimony: A Handbook of psychological research and forensic practice (pp. 129-146). Chichester, UK: Wiley.

Roberts, K. P., \& Cameron, S. C. (2004, March). An agenda for research in investigative interviewing: What do forensic interviewers want? Poster presented to the biennial meeting of the American Psychology-Law Society, Scottsdale, AZ.

Roberts, K. P., Lamb, M. E., \& Sternberg, K. J. (2004). The effects of rapport-building style on

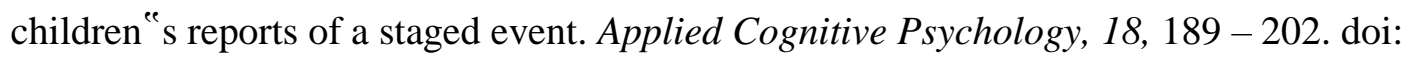
10.1002/acp.957 
Roberts, K. P., \& Powell, M. B. (2001). Describing individual incidents of sexual abuse: A review of research on the effects of multiple sources of information on children's reports. Child Abuse \& Neglect, 25, 1643-1659. doi: 10.1016/S0145-2134(01)00290-3

Roberts, K. P., \& Powell, M. B. (2005). Evidence of metacognitive awareness in young children who have experienced a repeated event. Applied Cognitive Psychology, 19, $1019-1031$. doi: $10.1002 /$ acp. 1145

Roberts, K. P., \& Powell, M. B. (2006). The consistency of false suggestions moderates children's reports of a single instance of a repeated event: Predicting increases and decreases in suggestibility. Journal of Experimental Child Psychology, 94, 68 - 89. doi: 10.1016/j.jecp.2005.12.003

Roberts, K. P., \& Powell, M. B. (2007). The roles of prior experience and the timing of misinformation presentation on young children's event memories. Child Development, 78, 1137 - 1152. doi: 10.1111/j.1467-8624.2007.01057.x

$S$ v. $R(1989)-168$ CLR 266

Sas, L. D., \& Cunningham, A. H. (1995). Tipping the balance to tell the secret: The public discovery of child sexual abuse. London, Ontario: London Family Court Clinic.

Saywitz, K. J., Esplin, P., \& Romanoff, S. (2007). A holistic approach to interviewing and treating children in the legal system. In M.-E. Pipe, M. E. Lamb, Y. Orbach, \& A.-C. Cederborg (Eds.), Child sexual abuse: Disclosure, delay and denial (219-250). New York, NY: Routledge.

Saywitz, K. J., Geiselman, R. E., \& Bornstein, G. K. (1992). Effects of cognitive interviewing and practice on children's recall performance. Journal of Applied Psychology, 77, 744 756. doi: 10.1037/0021-9010.77.5.744 
Saywitz, K. J., \& Snyder, L. (1996). Narrative elaboration: Test of a new procedure for interviewing children. Journal of consulting and clinical psychology, 64, 1347 - 1357. doi: 10.1037/0022-006X.64.6.1347

Schank, R. C., \& Abelson, R. P. (1977). Scripts, plans, goals, and understanding: An inquiry into human knowledge structures. Hillsdale, NJ: Lawrence Erlbaum Associates.

Schneider, L., Price, H. L., Roberts, K. P., \& Hedrick, A. (2011). Children's episodic and generic reports of alleged abuse. Applied Cognitive Psychology, 25, 862 - 870, doi: 10.1002/acp.1759

Sharman, S. J., \& Powell, M. B. (2012). A comparison of adult witnesses' suggestibility across various types of leading questions. Applied Cognitive Psychology, 26, 48-53. doi: 10.1002/acp.1793

Sharman, S. J., Powell, M. B., \& Roberts, K. P. (2011). Children's ability to estimate the frequency of single and repeated events. International Journal of Police Science \& Management, 13, 234 - 242. doi: 10.1350/ijps.2011.13.3.243

Slackman, E., \& Nelson, K. (1984). Acquisition of an unfamiliar script in story form by young children. Child Development, 55, 329 - 340.

Smith, K., \& Milne, R. (2011). Planning the interview. In M. E. Lamb, D. La Rooy, L.C. Malloy, \& C. Katz (Eds.), Children's testimony: A Handbook of psychological research and forensic practice (pp. 87-108). Chichester, UK: Wiley.

Sternberg, K. J., Lamb, M. E., Orbach, Y., Esplin, P. W., \& Mitchell, S. (2001). Use of a structured investigative interview protocol enhances young children's responses to free recall prompts in the course of forensic interviews. Journal of Applied Psychology, 86, 997 - 1005. doi: 10.1037/0021-9010.86.5.997 
Sternberg, K. J., Lamb, M. E., Hershkowitz, I., Yudilevitch, L., Orbach, Y., Esplin, P. W. \& Hovav, M. (1997). Effects of introductory style on children's abilities to describe experiences of sexual abuse. Child Abuse \& Neglect, 21, 1133-1146. doi:10.1016/S01452134(97)00071-9

Terr, L. (1990). Too scared to cry: Psychic trauma in childhood. New York, NY: Harper \& Row Publishers.

Terr, L. (1994). Unchained memories: True stories of traumatic memories lost and found. New York, NY: Basic Books.

Tidmarsh, P., Powell, M., \& Darwinkel, E. (2012). 'Whole Story'; a new framework for conducting investigative interviews about sexual assault. Investigative Interviewing: Research and Practice, 4, 33-44.

Trocmé, N., Fallon, B., MacLaurin, B., Sinha, V., Black, T., Fast, E., ... Holroyd, J., (2010) Canadian Incidence Study of Reported Child Abuse and Neglect - 2008: Executive Summary \& Chapters 1-5. Public Health Agency of Canada: Ottawa, 2010.

Tully, B. (2011). Expert testimony. In M.E. Lamb, D. La Rooy, L.C. Malloy, \& C. Katz, (Eds.), Children's testimony: A Handbook of psychological research and forensic practice (pp. 351-370). Chichester, UK: Wiley

Tulving, E. (2000a). Episodic memory and common sense: How far apart? Philosophical Transactions of the Royal Society of London B, 356, 1505 - 1515. doi: $10.1098 /$ rstb.2001.0937

Tulving, E. (2000b). Concepts of memory. In E. Tulving \& F.I.M. Craik (Eds.), The Oxford handbook of memory (pp. 33-43). New York, NY: Oxford University Press. 
Tulving, E. \& Markowitsch, H.J. (1998). Episodic and declarative memory: Role of the hippocampus. Hippocampus, 8, 198 - 204. doi: 10.1002/(SICI)10981063(1998)8:3<198::AID-HIPO2>3.0.CO;2-G

Walker, A. G. (1999). Handbook on questioning children: A linguistic perspective. Washington, DC: ABA Center on Children and the Law.

Whiting, B.F. (2013). An experimental evaluation of interviews containing a practice narrative. Regina, Saskatchewan, University of Regina (Unpublished MA thesis).

Wandrey, L., Lyon, T. D., Quas, J. A., \& Friedman, W. J. (2012). Maltreated children's ability to estimate temporal location and numerosity of placement changes and court visits. Psychology, Public Policy, and Law, 18, 79 - 104. doi: 10.1037/a0024812

Williams, J. M. G. (1996). Depression and the specificity of autobiographical memory. In D. C. Rubin (Ed.), Remembering our past: Studies in autobiographical memory (pp. 244-267). Cambridge, UK: Cambridge University Press.

Yuille, J. C., Cooper, B. S., \& Hervé, H. F. (2009). The Step-Wise guidelines for child interviews: The new generation. In M. Casonato, \& Pfafflin (Eds.), Pedoparafile: Psychological perspectives, forensic psychiatric. Italy: Franco Angeli (published in Italian). 